

\section{Avaliação e Sensibilização: um interjogo capaz de pormover e manter a busca da qualidade na educação.}

RESUMO: Como resultado de reflexões em torno da avaliação, elemento de gestão essencial para a busca de qualidade e eqüidade na educação, o presente trabalho visa analisar aspectos do processo de sensibilização no contexto da avaliação educacional. A sensibilização oportuniza a manutenção do fluxo de qualidade nos processos avaliativos, facilitando o engajamento e o fortalecimento do compromisso dos atores envolvidos. Serão focalizados pontos importantes para a compreensão das relações de causa e efeito na sensibilização a partir de motivos que impulsionam o ser a agir. Buscando problematizar as dificuldades que permeiam os processos de sensibilização e de avaliação em diversos contextos educacionais, será enfatizada a importância da sensibilização nas situações de negociação e desta para a avaliação da educação, fazendo breve referência às relações de poder na avaliação.

PALAVRAS-CHAVE: motivação, sensibilização, avaliação, educação.

O sentido de poder que tem a avaliação explica o grande protagonismo que ela exibe hoje em quase todos os âmbitos de intervenção social. É necessário insistir nessa afirmação para deixar claro que a avaliação não é simplesmente coisa de escola, nem somente da educação.

Ela ultrapassa largamente esses âmbitos e cada vez mais vem ampliando seus alcances e seus efeitos na economia e na política.

(DIAS SOBRINHO, 2002, p. 39).

\section{Introdução}

Desde a implantação do Ministério da Educação (MEC) em 1930, como um dos primeiros órgãos centralizadores da organização das políticas e dos processos educacionais, nunca a socie-
Maria de Lourdes O. Reis da Silva

Mestre em Educação

Professora da Rede Municipal de Ensino

lourdesreis@atarde.com.br 
dade brasileira presenciou um envolvimento tão acelerado e uma preocupação tão acirrada com a excelência e a competitividade na educação.

Os profissionais da educação queixam-se de que as instituições educacionais não acompanham esse processo de mudança e a própria profissionalização exigida pelos modos de produção determinam que as escolas e as instituições de nível superior se atualizem para atender às necessidades do mercado. As palavras de ordem são: produção, consumo, lucro e desenvolvimento sustentável, movidos pela evolução tecnológica que, a um só tempo, promove bem-estar, riqueza, exclusão e sufoca a percepção humana. Eleva a arte à exuberância dos efeitos especiais e embota as singularidades da cultura. Os conceitos de utilidade e necessidade superam os da ética e do sentimento. Antes era a barbárie da ignorância, da brutalidade, que eclodia aqui e acolá. Hoje é a barbárie do crime organizado, da tortura social pela falta de segurança; a barbárie tecnocrata, compartimentada, excludente e impiedosa para com aqueles que não conseguem vencer os obstáculos da competição.

Como aceitar um progresso que produz fome, ignorância e miséria social? Como encontrar o veio que nos conduzirá a caminhos que concretizem o progresso tecnológico e industrial sem massacrar o cidadão?

Pode-se ter a esperança de que a educação sensibilizará o homem no sentimento e no intelecto para a reconstrução social? Neste cenário de inquietações, a escola e a universidade se constituem em espaços de produção de conhecimentos que podem se tornar emancipatórios ou não. É a partir do contexto histórico e ahistórico que a educação deverá ser repensada e avaliada a fim de que se possam revitalizar as políticas e os programas educacionais, no sentido de superar as dificuldades e o baixo rendimento do alunado brasileiro. Não se pode mais aceitar de braços cruzados que a qualidade do ensino público continue nessa derrocada crítica, colocando o Brasil entre os piores desempenhos do mundo.

Este trabalho é o resultado de reflexões em torno da avaliação como precondição para a busca de qualidade e eqüidade na educação. Serão analisados aspectos conceituais, estruturais e organizacionais da avaliação e a importância da sensibilização como condição essencial para um processo mediador e emancipador. Contribuindo para fomentar o debate em torno da avaliação, de seus avanços, de seus retrocessos. 


\section{Reflexões conceituais em torno dos processos de motivação e sensibilização na avaliação da educação}

Para que se possam tecer considerações em torno da sensibilização no processo de avaliação da educação, torna-se necessário levantar alguns pontos concernentes à motivação, concebida como conduta humana. Motivação e sensibilização são variáveis do comportamento humano que aparecem inter-relacionadas nas situações da vida individual e coletiva.

\section{Motivação}

Bleger (1984) e Murray (1973), em suas considerações a respeito do assunto, chegam à conclusão de que a motivação é um fenômeno interno e está continuamente processando os incentivos do ambiente, dirigindo e integrando os comportamentos do sujeito em situações diversas.

Bleger (1984, p. 118) recorre ao conceito de causalidade operante para defini-la, "já que a motivação é também conduta e não um agente externo ou estranho ou distinto da própria conduta". A causalidade opera nos diversos níveis de integração da conduta: físico, biológico, social, e psicológico. Neste último, o autor denomina a conduta operante de motivação, que aparece como acontecimento, experiência (dramática).

Murray (1973, p. 20) diz que "um motivo é um fator interno que dá início, dirige e integra o comportamento de uma pessoa. Não é diretamente observado, mas inferido do seu comportamento (...)", supõe-se a sua existência a fim de se explicar o comportamento. Pode-se observar dois momentos distintos do motivo: o "impulso", processo interno que incita a pessoa a agir, podendo ser influenciado por um agente externo; e o momento da "recompensa", quando o "objetivo" foi atingido. A esse "impulso" interno os psicólogos chamam de motivação. Alguns afirmam que a motivação contém também "um desejo consciente" de obter algo. Outros acham que esta afirmação não tem valor científico. Preferem aceitar o comportamento influenciado por um motivo inferido.

Cofer e Appley (1976, p. 20-23) desenvolveram um estudo sobre as diversas teorias da motivação e selecionaram alguns conceitos relevantes para a compreensão do comportamento motivado. Vale destacar os seguintes: segundo Young, motivação é "o processo para despertar a ação, sustentar a atividade em pro- 
gresso e regular o padrão de atividade." Para Murphy, motivação é em geral o nome "que se dá aos atos de um organismo que estão, em parte, determinados por sua própria natureza ou por sua estrutura interna." O termo motivação foi empregado por Maier objetivando "caracterizar o processo que determina a expressão da conduta e influi em sua futura expressão por meio de conseqüências que a própria conduta ocasiona."

Nérici (1985, p. 76) diz que a "motivação resulta de um complexo de necessidades de caráter biológico, psicológico e social." O autor considera a motivação como "uma força interior que provoca interesse por alguma coisa" (p. 78), mas que poderá ser reforçada por uma influência exterior, a partir de situações criadas que levam o sujeito a desejar realizar algo, que pode ser tanto no campo da aprendizagem, como em outras processos e atividades.

Os conceitos acima explicitados sinalizam que a motivação é um processo interno, complexo e difícil de ser definido objetivamente, mas de grande importância como uma das causas da conduta. No caso em pauta, analisa-se a importância da motivação nos processos de sensibilização e avaliação educacional. Concluindo que a sensibilização se instala no comportamento humano a partir da motivação, auto-regulada pelo interjogo das relações que se operam entre os campos da conduta humana.

\section{Motivação social como fator de sensibilização}

O presente estudo não pretende analisar os aspectos da motivação na aprendizagem, mas a motivação social, no âmbito da sensibilização para o engajamento nos processos de avaliação da educação.

A motivação social reveste-se de alguns aspectos relevantes para a sensibilização e envolvimento das pessoas em atividades diversas, como: busca de padrão de excelência, desejo de alcançar sucesso e filiação em movimentos políticos e socioculturais. Segundo Murray, os motivos sociais, sejam inatos ou aprendidos, dominam a maior parte do comportamento humano. Os vinte motivos sociais listados por Murray (agressão, amparo, atividade lúdica, autonomia, deferência, defesa, domínio, entendimento, evitação de danos, exibição, filiação, nutrimento, ordem, passividade, reação, realização, rejeição, sensualismo, sexo), revelando facetas do comportamento humano, foram inferidos de histórias 
imaginativas a partir do estudo com grupos de pessoas, de forma intensiva, aplicando questionários, entrevistas e testes psicológicos. O autor destaca especialmente dois motivos: motivação para a realização e motivação para a afiliação. Foi observado que, principalmente nas situações de aprendizagem, os sujeitos com alto nível de motivação para a realização respondem melhor quando são colocados em situações de desafio, escolhem parceiros que sejam especialistas e que contribuam para a realização das tarefas. Enquanto que os indivíduos de elevada motivação para a afiliação valorizam mais a amizade, o companheirismo e a formação de grupos com objetivos comuns. (cf. MURRAY, 1973, p. 151-173).

Pode-se considerar que, independentemente da origem dos motivos sociais, se inatos ou aprendidos, a motivação social em seus múltiplos aspectos, tem fundamental importância nos processos educacionais, uma vez que os sujeitos se movimentam a partir de suas necessidades existenciais. Os motivos sociais necessitam, para expressarem-se, da presença ou da participação de outros indivíduos da mesma espécie e os motivos individuais "contribuem para a defesa e revigoração a imagem que cada pessoa possui de si mesma." (BRAGHIROLLI, 1995, p. 101).

Portanto, em um programa de sensibilização para a avaliação da educação, considerar, valorizar e analisar as implicações decorrentes dos motivos de cada ator do processo irá contribuir para a consecução dos objetivos propostos; necessitando, incontornavelmente, de investir na auto-avaliação, a fim de que esses atores comprometidos com o processo, evitem assumir posições radicalizadas, decorrentes dos mesmos motivos que os impulsionam à participação.

O ambiente educacional comporta todos estes aspectos, podendo-se associá-los, principalmente, à busca de padrão de excelência no âmbito da avaliação em larga escala. Observa-se, contudo, que os processos avaliativos desenvolvidos pelo Estado primam pela característica coercitiva, negligenciando o aspecto da sensibilização, forma eficaz para que se possa legitimar a adesão voluntária e qualitativamente mais efetiva na avaliação do ensino; capaz de promover a melhoria da educação pelo envolvimento, comprometimento e participação de educadores e educandos. Fala-se aqui da adesão voluntária no sentido do envolvimento dos atores educacionais no processo da avaliação, e não da participação no serviço social voluntário. 
(1) Debate em torno do tema: Territorializacão, desterritorialização, inconsciente maquínico, construção de subjetividades, diário de itinerância e Etnopesquisa Formação, em 06/03/2003. Programa de Pós-graduação em Educação. FACED/ UFBA
A adesão voluntária parte de princípios e motivos para a afiliação, tais como: relação humana rica e solidária, doação de energia e criatividade, compromisso e retorno na satisfação de ser útil, ação duradoura e qualitativa, vivenciando as diferenças, transformando-se em ferramenta de integração social; a excelência na execução das tarefas é movida por princípios e motivos para a realização, fundantes na busca de eficiência e eficácia. A inter-relação destes fatores e não a negação de um ou outro, integram de modo qualitativamente positivo, o processo de sensibilização para a avaliação da educação.

\section{A sensibilização no âmbito dos processos avaliativos}

Todo e qualquer processo de avaliação deverá decorrer de um diagnóstico o mais fiel possível da situação a ser analisada, seguido de um trabalho de sensibilização dos atores a partir de atividades em que a participação e o engajamento possam permear todo o processo. A sensibilização não deve ser um momento isolado, promocional, mas efetivo, em que os membros se sintam motivados a colaborar, sem o risco de futuras punições ou perspectivas de premiações. Sempre que o exercício da confiança não é oportunizado nos processos grupais, o risco do boicote é inevitável, pois que as pessoas se sentem ameaçadas, recusando-se a colaborar com as atividades.

As manifestações do inconsciente maquínico (atmosfera psíquica do objeto a ser investigado) se fazem sentir e seus efeitos são quase sempre danosos. São processos que articulam sentido e formam redes e agenciamentos conduzindo o grupo a assumir uma atitude de imostrabilidade, camuflamento da realidade sob a aparência ora de indiferença, ora de negação ou agressividade. Essa cadeia de significados é movida pelos desejos individuais e grupais que se aliam contra um suposto personagem que ameaça a integridade do grupo (informação verbal) ${ }^{1}$, um terceiro excluído, que pode muito bem ser identificado com "o convidado impertinente", profissional convidado pela instituição para realizar um trabalho de auto-avaliação; com "o espião que veio do frio", profissional enviado pela administração central a qual está vinculado ou por organização independente; ou com "o curioso que passava por ali", geralmente representado pelo sociólogo, psicossociólogo e pelo etnólogo, profissionais engajados em pesquisas educacio- 
nais; papéis estes, analisados por Perrenoud (1998). Todos esses profissionais necessitam estabelecer seu trabalho com muita clareza, a fim de certificar-se até que ponto o grupo está concordando com a avaliação ou pelo menos não se opõe a ela.

A sensibilização deverá ser desenvolvida como um processo retroalimentador e mantenedor do fluxo de qualidade e pertinência, visando aliviar tensões e desconfianças, sem o que qualquer trabalho de pesquisa ou avaliação poderá fracassar ou assumir a feição de obrigatoriedade. Na busca de bons índices de qualidade, principalmente quando esta envolve conduta humana, o caráter de essencialidade alcança melhores resultados, quando bem apreendido a partir do processo de sensibilização, do que o de obrigatoriedade.

De um lado, torna-se evidente a necessidade de incentivar, sensibilizar os atores da educação para um trabalho consciente de avaliação, com o fim primordial e permanente de promover novas políticas de expansão e eqüidade, sem camuflagens e embotamentos. Por outro, torna-se imprescindível que os sujeitos envolvidos nos processos educativos desenvolvam a consciência plena da importância de suas contribuições, a partir do desejo de concorrer para a reestruturação da educação em nosso País. Neste aspecto, desejo é disponibilidade, motivação, compromisso, envolvimento; contém algo de libidinal (diferente de sexual), de construtivo, expressado a partir da produtividade dinâmica dos parceiros em ação. Isto é estar sensibilizado, estado de prontidão para fazer acontecer, não apenas em proveito próprio, mas, acima de tudo, pelo bem comum, que, no caso em pauta, é a educação bem sucedida.

Pode-se concluir que os níveis, a qualidade e os efeitos da sensibilização diferem a partir dos objetivos de pessoas e instituições, dos motivos que os impulsionam a agir.

Observa-se no Sistema Educacional Brasileiro uma certa inquietação por parte da política mantenedora dos programas de avaliação, como se estivesse acontecendo nesses organismos uma sensibilização compulsória, ânsia de avaliar, de colher resultados, pela metodologia do exame, vale salientar. Em virtude dos freqüentes resultados negativos apresentados pelas agências, pergunta-se: $\mathrm{O}$ que fazer com esses resultados? Como as escolas estão contabilizando esses baixos índices de desempenho do alunado brasileiro? Qual está sendo o benefício para o aluno em toda essa corrida? 
(2) Encontro de Cipriano Luchesi com alunos do curso de Pós-graduação da FACED/UFBA, em fevereiro 2003.
Por outro lado, sensibilização competitiva se faz sentir nos meios educacionais e acadêmicos em função da disputa por excelência nem sempre comprovada. A relação de Estado Avaliador passa a se configurar como Estado Fiscalizador, fugindo dos princípios delineados na LDB, fortalecendo essa corrida pelos melhores conceitos das instituições. Dessa forma, a avaliação da aprendizagem que deveria funcionar como ponto de partida para a avaliação de programas nos diversos níveis de ensino e da formação profissional, nesse contexto das avaliações atuais esgotase em si mesma, mais como uma política de resultados do que como proposta de ações inovadoras, de implicações mais procedimentais do que processuais. No dizer de René Barbier,

um processo apresenta uma polarização de autonomia repleta de incertezas [ao passo que] um procedimento, ao contrário, visa sempre controlar, por sua formalização regulamentar e arbitrária (...). Posso controlar um procedimento, mas eu avalio um processo. (2002, p. 111).

O professor Cipriano Luchesi considera que, sendo a avaliação um processo norteador da aprendizagem, o nosso sistema educacional, pelos procedimentos adotados, não avalia, apenas examina (Informação verbal) ${ }^{2}$. Refletindo sobre as afirmações de Barbier e Luckesi, constata-se, mais uma vez, que as agências de avaliação e os professores em sala de aula desenvolvem procedimentos de exame e compilação de resultados, enfatizando os aspectos quantitativos em detrimento dos qualitativos. Procedimentos estes, que se distanciam dos princípios decantados na legislação e nas diretrizes curriculares editadas pelo MEC e pelas Secretarias estaduais e municipais, a partir de 1996.

A prática da avaliação na educação vem sendo, historicamente, um procedimento que não tem sensibilizado estudantes e professores para encarar os resultados, no que concerne a seu próprio desempenho, em atitude de análise, com vista a mudanças realmente significativas. O medo da crítica destrutiva e da punição, decorrente da falta de confiança do ser humano no seu semelhante e, conseqüentemente na legitimidade dos processos; as condutas defensivas diante de resultados insuficientes, contribuem para que esses resultados funcionem como ponto de estrangulamento do processo e não como fluxo de ação renovadora. Tanto alunos como professores continuam buscando apenas no 
outro, ou no sistema, as causas dos desacertos, ignorando, na prática, a realidade de sua incompletude e inacabamento; impedindo a discussão ampla e aberta a respeito de desempenho e de práticas discente e docente. Pode-se assinalar como causa, a dificuldade de sensibilizar com sensibilidade, com solidariedade, gerando desconfiança e afastamento entre os atores da educação e produzindo um território individualista, onde a disputa por posições e espaços inibe o processo de avaliação.

\section{A sensibilização nos processos de negociação}

Um outro aspecto de relevância na avaliação que não prescinde de sensibilização é a negociação. São várias as formas de negociação: trabalhista, diplomática, comercial, administrativa e política. De todas elas, pode-se considerar a política como a mais excelente para os processos de avaliação educacional. Este tipo de negociação valoriza a diversidade e busca a unificação de objetivos, idéias e propostas, num processo dinâmico de produção de sentidos e solução de problemas. É também a mais difícil de ser implantada, pelo fato de que já se firmou em muitos setores da sociedade o hábito da negociata, dos acordos fundados em trocas de favores que beneficiam uma minoria. A negociação em educação deverá ser delineada como "mediação/desafio de cada instante, notadamente nos grupos interculturais". (BARBIER 1983, apud BARBIER 2002, p.110).

A questão da interculturalidade na educação brasileira tem sido ainda tema de debates, no desenvolvimento de projetos que discutem a inclusão, muitas vezes permeada de decisões insatisfatórias. Fala-se de inclusão, enquanto se deveria estabelecer o compartilhamento, o vivenciamento. A idéia de inclusão traz um sentido de valor onde o incluído é sempre o quê está em segundo plano, em situação discriminatória e inferiorizante. Observa-se que o "incluído" passa a sofrer uma outra situação: a exclusão e a violência simbólicas através da rejeição e da indiferença em relação às suas necessidades. Torna-se necessário, portanto, o encaminhamento de um programa de avaliação desse processo, a fim de que se possa encontrar soluções viáveis, que evitem a dupla humilhação do incluído. 


\section{Características da negociação política e sua relação com a avaliação na educação}

A principal característica da negociação política é a exigência da divulgação de seus resultados, não podendo permanecer ocultos os acordos realizados no âmbito das negociações. Entretanto, alguns compromissos necessitam, em determinadas situações, de ser preservados do domínio público, não isentando as partes da obrigação de publicar os seus resultados. (cf Zajdsznajder, 1988, p. 18). A negociação que o MEC estabelece com as comunidades estrangeiras para a obtenção de fundos e parcerias, distingue-se das estabelecidas entre os seus diferentes órgãos, nas instituições, entre os educadores e a comunidade em geral. Entre o MEC e os financiadores estrangeiros estabelece-se, principalmente, uma relação de troca, em que o governo brasileiro se compromete a apresentar melhores índices de alfabetização, de aprovação e de alunos matriculados. A idéia de qualidade não deixa de estar embutida na proposta, entretanto, o que vigora ainda são os resultados quantitativos. Entre os órgãos do ministério, a relação estabelecida é, via de regra, a parceria, que é também firmada entre MEC e empresas. Entre o ministério e as instituições educacionais, além da parceria, destaca-se em primeiro plano a legislação e a regulamentação. No contexto das instituições educacionais, quando se trata de avaliação interna, a negociação se reveste de um caráter essencial, no sentido de estabelecer um clima de confiança e colaboração, devendo ser instituída a prática da sensibilização constante, a fim de garantir a continuidade do processo. Neste caso, o compromisso da divulgação dos resultados é com a comunidade escolar e demais atores envolvidos, como pais de alunos e entidades participantes.

A negociação política, estando presente nos diferentes setores da sociedade, em cada um deles assume formas diferenciadas, peculiares de cada realidade e não prescinde do estabelecimento de acordos e captação de apoios. Tanto a negociação política quanto os seus objetos estão condicionados por normativas e padrões ideológicos, da sociedade em geral, de grupos políticos e/ou instituições. Ainda que as negociações não se caracterizem como luta de poderes, encontra-se presente em toda negociação, o poder de barganha, do qual as partes negociantes estão munidas. (cf Zajdsznajder, 1988, p. 4-18). Afirma o autor 
que a realidade do poder encontra-se presente nas negociações de um modo específico: nem sempre de modo direto e imediato, constitui por assim dizer uma realidade circundante quase-visível que possa ser trazida ao processo de negociação, seja para auxiliá-lo, seja para destruí-lo.

Outros aspectos relevantes na negociação política são as questões econômicas, envolvendo a captação e utilização de recursos; planejamento, organização e processo decisório; utilização de táticas e estratégias com vista ao acordo; elementos de jogo, movimentos que se constituem em lances de uma partida sem resultados predeterminados. (cf Zajdsznzjder, 1988, p. 19-22).

Gonçalves filho (2000, p. 11-27), ao analisar a importância da literatura na educação, se refere com muita propriedade ao "poder da palavra" e à "palavra do poder", afirmando que "só os que têm ou detêm o poder de alguma coisa é que tem o poder da palavra. [...] a palavra, por ser assim instrumento tão poderoso sobre o mundo, acaba, feito o ouro ou o dólar, sendo instrumento de poucos.

O autor enfatiza o poder da palavra e da literatura como produtoras de conhecimentos, veiculando socialmente valores culturais e contribuindo para a inserção de homens livres na sociedade. Mas, o que esse poder tem a ver com sensibilização e avaliação, e de que forma pode auxiliar o nosso raciocínio?

No uso da palavra, o homem está constantemente construindo ou destruindo, firmando alicerces, delineando territórios, estabelecendo relações, tecendo uma cadeia de significados que the confere maior ou menor estabilidade entre seus semelhantes. Essa palavra, a depender de quem a fala, do seu domínio sobre ela, soa com maior ou menor poder de sensibilização. Entretanto, a palavra, para sensibilizar, precisa estar carregada de significados, de sentidos éticos e, relembrando o autor, se transformar numa "espécie assim de Aladim e sua lâmpada maravilhosa" ( $p$. 19). E nem sempre os educadores, os gestores da avaliação estão munidos dessa ferramenta, a palavra sensibilizadora, investindo na relação autoritária, conferida pela "palavra do poder". Esta consegue alcançar seus objetivos legislando, contudo, não tem o poder do envolvimento, da arte de tornar sensível aquele que a ouve. É neste sentido que a avaliação da educação esgota-se em si mesma e os seus resultados fazem mais estragos do que benefícios, porque não promovem mudanças, repetindo-se através dos tempos, empurrando para o futuro o sonho da educação. 


\section{Reflexões finais}

A discussão sobre avaliação ganha amplos espaços nos meios educacionais e torna-se necessário promover o debate em torno da importância da sensibilização e da conscientização dos educadores, para a necessidade de um processo mais abrangente de avaliação nas instituições de ensino em todos os níveis.

Continuar utilizando velhos padrões em avaliação, permanecer em atitude de crítica estéril, atribuir o fracasso escolar apenas à postura dos alunos e às condições familiares, são atitudes que não conduzirão a uma mudança efetiva na educação. É preciso refletir sobre a participação de cada um nesse processo, sobre o desempenho institucional; através de uma política de avaliação interna em articulação com a avaliação em larga escala que o MEC vem desenvolvendo; e que proporcione resultados válidos para a tomada de decisão e a implantação de melhorias. Se na Educação Superior já existem experiências de Avaliação Institucional, na Educação Básica esse quadro ainda não se delineia com nitidez. Ainda não se saiu do terreno das reflexões para uma prática efetiva e construtiva.

Um aluno da universidade fez uma interessante narrativa, ao se discutir em sala de aula a questão da qualidade da educação:

Pertencente a uma extensa família pobre, de um bairro de periferia, ele era entre os seus irmãos, o único que não abandonara a escola e conseguira entrar para a universidade. Seus irmãos desistiram da escola e cada um partiu para aprender um ofício e ganhar a vida, como se diz popularmente. Um deles seguiu a profissão de mecânico e estava em boa situação financeira, em condições inclusive de ajudar o irmão universitário. Todos declaravam, segundo o aluno, que a escola não lhes tinha oferecido qualquer diretriz para que eles pudessem sobreviver com dignidade. Pergunta-se então: Por que alguém que abandona a escola por não conseguir um desempenho satisfatório aprende na vida prática, se insere numa profissão? Qual o problema da escola? Queremos um país com profissionais no mercado de trabalho que assinam o nome, mas não são alfabetizados? Para onde esta situação conduzirá o país? (SILVA, 2004, p. 37).

Enfatiza-se, portanto, a necessidade da sensibilização no âmbito das políticas públicas, no interior das instituições educacionais, no contexto das relações entre educadores, educandos, 
familiares e sociedade, a fim de que se possa pensar e discutir avaliação em seu sentido mais essencial que é o de promover a qualidade na educação. E a importância de instituir o seu sentido ético e estético para aprimorar as relações de poder que se estabelecem no contexto educacional, valorizando a participaçãoação, o valor intrínseco de cada ator institucional e social.

\begin{abstract}
As a result of reflections on evaluation, an essential management element in the search for quality and equity in education, the present work aims analysing aspects of sensitizing process in the context of educational evaluation. Sensitization offers an opportunity of keeping the quality flow in the evaluating processes, making easier the engagement and solidity of the actors' involved. Having the motives that impel human beings to act as a starting-point, we will be focusing on important aspects for the understanding of the cause-effect relations in sensitization. With the objective of problemizing the difficulties that interpose the sensitization and evaluation processes in various situations, the importance of sensitization will be emphasized in the negotiation situations and, from there, to the education evaluation, making a brief reference to the power relations in evaluation.
\end{abstract}

KEY WORDS: motivation, sensitization, evaluation, education.

\title{
Referências
}

BARBIER, René. A pesquisa -Ação. Lucie Didio (Trad.). Brasília : Editora Plano, 2002.

BLEger, José. Psicologia da Conduta. 2 ed. Porto alegre : Artes Médicas, 1984.

BRAGHIROLLI, Elaine Maria et al. Psicologia Geral. 12 ed. Petrópolis: Vozes, 1995.

Bruxelas. Comisión de las Comunidades Europeas. Enseñar y aprender: hacia la sociedad cognitiva: Libro Blanco sobre la educación y la formación, 1995.

COFER, C. N.; APPley, M. H. Psicologia de la motivación. Teoria e investigación. México: Editorial Trillas, 1976.

DIAS SOBRINHO, José. Campo e Caminhos da Avaliação: a avaliação da educação superior no Brasil. In: Avaliação: construindo o campo e a crítica / Luiz Carlos de Freitas, (Org.). Florianópolis: Insular. 2002.

GONCALVES FILHO, Educação e Literatura. Rio de Janeiro: DPÉA, 2000 . 
MURRAY, Edward J. Motivação e Emoção. 3 ed. Rio de Janeiro : Zahar Editores, 1973.

NÉRICI, Imídio G. Didática - uma introdução. São Paulo: Atlas, 1983.

PERRENOUD, Philippe. Avaliação - Da Excelência à Regulação das Aprendizagens. Entre Duas Lógicas. Porto Alegre : Artes Médicas Sul, 1998

Silva, Maria de Lourdes O. Reis da. Características teóricas, políticas e epistemológicas da avaliação institucional em uma escola da rede pública estadual de ensino. Dissertação de Mestrado. Salvador: FACED/UFBA, 2004.

ZAJDSZNAJDER, Luciano. Teoria e prática da negociação - política de negociação. 2 ed. Rio de janeiro: José Olympio, 1988. 